\title{
Obstacles Facing Disabled People in Accessing the Historical and Archaeological Sites in Jordan
}

\author{
Mohammad Abed Sakarneh \\ Associate Professor, Department of Special Education, \\ Princess Rahma University College, Al Balqa Applied University, \\ P.O.Box. 206, Salt 19117, Jordan \\ Hiam Jameel Katanani \\ Associate Professor, Department of Special Education, \\ Princess Rahma University College, Al Balqa Applied University, \\ P.O.Box. 206, Salt 19117, Jordan
}

DOI: https://doi.org/10.36941/jesr-2021-0045

\section{Abstract}

Despite the growing numbers of disabled individuals in the global population, issues of accessibility prevent them from accessing tourism sites and leisure activities. The purpose of this study is to identify the obstacles preventing people with disabilities from accessing historical and archaeological sites in Jordan. Using a sample of disabled people in Jordan and structured questionnaires, their views are collected and analyzed quantitatively. Descriptive statistics was used in the study to highlight the different features and perceptions of disabled people in relation to accessing tourism and leisure activities. The main issues identified as obstacles include the intrinsic factors such as their fear of doing something by themselves and the requirements imposed by their disabilities in accessing the services.

Keyword: Accessing, Archaeological Sites, Disabled People, Historical sites, Obstacles

\section{Introduction}

\section{$1.1 \quad$ Background}

Tourism is among the most important industries in the global economy since it helps communities to generate income by showcasing what they have and inviting visitors to experience it. Additionally, tourism can be perceived as a basic human right that should be accessible to all individuals irrespective of their social status or other characteristics (WTO, 2020). This is very important especially when talking about people with disabilities because they are likely to be unable to access certain facilities.

People with disabilities may be limited from accessing certain facilities and leisure activities due to barriers and constraints despite their growing numbers in the global population. People with disabilities account for about $10 \%$ of the global population and present a niche market for tourism (World, 2013). The issues of people with disabilities in the Middle East are direr because they are mostly considered from a 
charity and medical approach very narrowly. Inclusivity for people with disabilities in all aspects of life is essential. In Jordan, disability prevalence is estimated at about $11 \%$ to $15 \%$. For people over 65 years, the disability prevalence is $13.9 \%$ despite the group accounting for $6 \%$ of the population (Thompson, 2018).

Tourists with disabilities present a niche market globally worth over $\$ 120$ billion. However, as indicated in Allan (2013), the attention directed to this market in Jordan has been inadequate. The country is a party to the UN Convention on the rights of people with disabilities, which seeks to enhance the quality of life for people with different disabilities (Allan, 2014). Allowing these people access to tourism activities and destinations would be a key element of their rights (European Commission, 2015; Higher Council for the Rights of Persons with Disabilities, 2017; Sakarneh, 2014).

\subsection{Problem Statement}

Despite the measures for promoting accessible tourism, the involvement of people with disabilities in tourism activities in Jordan has been heavily limited. This study seeks to address the issue by assessing the factors that hinder these individuals from participating in tourism.

\section{$1.4 \quad$ Research Questions}

The main issue that the research seeks to address is "What are the obstacles facing disabled people seeking to access historical and archaeological sites in Jordan?"

The main research question will be addressed alongside other sub-questions as identified below:

Q1. Which physical aspects of the historical and archaeological sites act as obstacles to access for disabled people?

Q2. Which intrinsic or attitudinal factors act as obstacles to access?

\section{Literature Review}

\subsection{Accessible Tourism}

Tourism for people with disabilities generally referred to as accessible tourism refers to tourism that is accessible to all people irrespective of whether or not they have physical or other disabilities. It involves inclusive tourism that is accessible to individuals who may have cognitive, mobility, hearing, sight, or even intellectual disabilities. It involves making efforts to cater for the needs of a wide range of consumers by removing institutional or attitudinal obstacles. The delivery of universal tourism products is critical as an aspect that enables such individuals to function independently and enjoy the attractions on offer in a destination.

\subsection{The Market for Travelers with Disability}

The WHO indicates that about $15 \%$ of the global population (1 billion people) lives with different disabilities. These individuals have civil rights and expect to be treated with dignity and equality. We have a social responsibility to ensure that people with disabilities have access to an obstacles free environment.

People with different types of disabilities present a growing business opportunity. The practice is gaining momentum across countries due to its relevance as a human rights issue and its contribution to economies (Das \& Rudra, 2015). The strategies adopted and how tourism is organized results in disabled tourists being excluded from many locations and leisure activities. The need for these individuals to feel included and to have their interests considered in the design and operation of tourist attraction sites is a major factor contributing to the trend towards their increased adoption. 


\subsection{Inhibiting Factors}

Accessible tourism in many countries has not been achieved owing to a number of factors that have been identified in the research. Empirical studies such as Bahulis (2011) have sought to identify the factors that limit access to tourist destinations for people with disabilities. These included inadequate social construct, lack of medical interventions, a poor environment, negative attitudes, and lack of government support. In the study, which involved interviews with paraplegic individuals, lack of physical accessibility was a key obstacle.

In a review by Das and Rudra (2015), the key elements in motivating people with disabilities to participate in tourism activities were identified. They were categorized into 3 groups: physical accessibility; accessibility information and presentation of the same in effective locations (Tecău et al, 2019). Destination facilities such as restaurants, museums, and cultural heritage sites require features that make them accessible such as ramps for wheelchairs and effectively designed paths. Proper and accurate information about the accessibility features is also necessary for helping tourists and their families with the planning.

While accessibility features are important, information about the features and how they are organized to respond to customer needs is necessary. This helps the tourists in making informed decisions as well as effective planning of their trips. Facilities may be accessible, but if they fail to provide reliable and sufficient information, they may not seem attractive to prospective disabled visitors. Richness of information that is inclusive and detailed is a major factor that is considered in helping visitors to plan a holistic travel experience. The third element is how the accessibility information about tourist destinations is presented in an accessible manner. This may include having screen readers, braille displays, voice recognition and alternative input devices. This requires the design of flexible websites that can be used by the different assistive technologies to make it fully accessible (Yau, McKercher, \& Packer, 2013).

\subsection{Accessible Tourism and the Long Tail Theory}

The high level of competition in the global economy and increased accessibility to information coupled with technological advancements has significantly changed business models. One of the major changes in the business and management environment is the increased focus on the $80 \%$ of products and market that are not very popular. Instead of focusing on the most popular $20 \%$ of products at the expense of the remaining ones, companies also invest in developing products to address the needs of the remaining $80 \%$ through enhanced customization (Wu \& Cheng, 2008).

Another key principle of the long tail theory is that no single product can address the needs of all consumers. This means while the average consumer may be satisfied with one kind of a package, not all needs will be met using it. The disabled individuals have a right to enjoy travel and leisure activities. They require the right accessibility strategies and options for enabling them to enjoy the experiences (Wu \& Cheng, 2008).

\subsection{Accessible Tourism in Different Countries}

Different countries in Europe have implemented accessibility schemes in line with the legislation in place. For example, an accessibility scheme was initiated in Denmark in 2004. It involves the provision of information in four languages. Organizations register and have the opportunity to be accessibility labeled. The program, Access Denmark, features the schemes of 7 different types of disabilities. It is not only an information site, but also functions as a marketing tool for destinations. This aspect has been improved with the introduction of specific legislation preventing facilities and operators from discriminating against people on the basis of their disabilities (Pedersen, Andersen \& Jorgensen, 2016).

In the UK, accessible tourism is addressed through the Disability Discrimination Act of 1995. It provided a platform where improvements in accessibility for tourist attraction sites could be enforced 
by law. As cited in Shaw and Coles (2004), the tourism council of England engaged in efforts to explain the economic benefits of a tourism approach that addresses the needs of all people.

\subsection{The Case of Jordan}

Empirical studies have been conducted in Jordan to assess the practice of accessible tourism. In a quantitative study by Allan (2014), a sample of tourists with disabilities was engaged. The aim was to identify the factors that acted as motivations for tourists with disabilities. The results indicated that the most important motivators for tourists were relaxation, the escape factor, and enjoyment. The results indicated that the main extrinsic factors involved externalization of the intrinsic motivations. They concluded that there is a high congruence with the values that are important to the tourism experience. The results of Allan (2004) also indicate that the experience may be more adverse for tourists with disabilities because of negative attitudes and inaccessibility to some activities. The most significant barriers were intrinsic as opposed to extrinsic.

Allan (2013) found that the key motivators for disabled tourists in Jordan were to gain a sense of freedom and for enjoyment of interest. The study also indicated that cultural and historical attractions were the most relevant as motivators of the tourism activities.

Jordan is home to many historical sites and monuments. The country has invested heavily in restoring the sites and making them attractive to visitors. The historical sites in Jordan attract millions of visitors annually who are interested in learning the cultural heritage of the country (Alsarayreh, 2019; Sakarneh, Paterson \& Minichiello 2016) Some of the strategies adopted in making tourism and historical sites more accessible include the adoption of electronic tourism. Bazazo \& Alananzeh (2016) presented a research study where the adoption of electronic tourism and assistive technologies was evaluated. They found significant weaknesses in the assistive technologies adopted for helping disabled tourists.

According to a 2017 report by global accessibility news, archaeological sites were found to be inaccessible to people with disabilities in Jordan. People with disabilities felt that they were being denied access to these sites due to the lack of facilitation. Some of the main issues with the sites include the absence of wheelchair ramps and lack of other health utilities. Transportation challenges in the archaeological sites and not having adequately trained people to deal with the disabled tourists is another major issue (GAN, 2017). People with disabilities need a lot of help from other individuals in order to effectively navigate and visit the archaeological sites, which hampers them significantly.

\subsection{Research Gap}

The main gap identified in the research regarding the issue of accessible tourism in Jordan is that there is limited information on the factors that influence disabled people and limit them from accessing tourist sites. There is a need for further research on the factors and issues that act as obstacles for disabled people in Jordan and prevent them from accessing tourist sites.

\section{Research Methodology}

The focus of the study is to evaluate factors that influence disabled people and their access to historical sites. It sought to identify the intrinsic factors and physical obstacles that have a potential impact on how disabled individuals can access historical sites in Jordan. It seeks to build on knowledge that has been acquired in prior studies. As a result, a quantitative approach was adopted for the study to ensure that the researchers had the opportunity to gather numerical data that would be used to identify the views held by the participants about accessible tourism and what it means to people in Jordan.

The focus of the study is on people with disabilities in Jordan. As a result, the sample had to be derived from this population to ensure that it would be effective in gathering valid information. The sample was derived from different institutions in Jordan such as the division for supporting students with special needs at the Al-Ahliyya Amman University, Yarmouk University, The University of Jordan 
and Mutah University. The focus on these samples was based on the fact that the study focused on the obstacles to engagement in tourism activities hence it was not necessary to use tourism organizations as the sampling frame. The sample was sought from university students with disabilities because they were accessible and could be sampled easily. Questionnaires were sent to all registered students in deanships of student affairs in the regarded universities. This was done with the permission of the regarded universities and the contact details of the student provided by them.

The study was undertaken using a structured questionnaire that consisted of two sections: travel constraints and intrinsic motivation. The items assessing travel constraints were derived from a prior study by Lee and colleagues (2012). The nonphysical obstacles could be emotional, attitudinal or psychological. They highlight lack of motivation to engage in the identified activities. The questionnaire items for the motivation of tourists were derived from Deci and Ryan (2004). All items in the questionnaire consisted of Likert Scale answers that were used to rate the responses from the participants. The rating scale consisted of 5 points ranging from not true (1) to true (5) hence higher scores indicated stronger agreement with the identified issues. The collected data was analyzed using the Statics Program for Social Sciences (SPSS) and provided an opportunity for descriptive and inferential statistics to provide a deeper analysis of the issues.

\section{Results}

A total of 200 questionnaires were distributed to the sampled respondents and they were asked to fill them onsite. The researchers gave the participants the respondents the opportunity to fill the questionnaires at their convenience and support for provided in line with their disabilities. Of the 200 questionnaires that were given out, 189 , were used in the analysis, 11 were incomplete and could not be effectively applied.

\subsection{Descriptive Statistics}

The demographic characteristics of the participants are presented here. Among the 189 valid questionnaires, men accounted for $55.6 \%$ while the women made up $44.4 \%$. In terms of age, most of the respondents were relatively young with $36 \%$ being $18-25$ years while $25.4 \%$ were in the age bracket of $25-29$ years. Only $7.9 \%$ of the respondents were above 50 years old.

Table 1: Demographic Characteristics

\begin{tabular}{|c|c|c|c|}
\hline Gender & Male & 105 & $55.6 \%$ \\
\hline & Female & 84 & $44.4 \%$ \\
\hline \multirow[t]{5}{*}{ Age } & $18-25$ & 69 & $36.5 \%$ \\
\hline & $25-29$ & 48 & $25.4 \%$ \\
\hline & $30-39$ & 33 & $17.5 \%$ \\
\hline & $40-49$ & 24 & $12.7 \%$ \\
\hline & $50+$ & 15 & $7.9 \%$ \\
\hline \multirow[t]{3}{*}{ Education level } & Diploma & 55 & $29.1 \%$ \\
\hline & undergraduate & 88 & $46.6 \%$ \\
\hline & postgraduate & 46 & $24.3 \%$ \\
\hline \multirow[t]{5}{*}{ Annual income (JOD) } & $<3,000$ & 86 & $45.5 \%$ \\
\hline & $3,001-6,000$ & 52 & $27.5 \%$ \\
\hline & 6,001-9,000 & 28 & $14.8 \%$ \\
\hline & 9,001-10,000 & 15 & $7.9 \%$ \\
\hline & $>10,000$ & 8 & $4.2 \%$ \\
\hline \multirow[t]{5}{*}{ Disability type } & Visual & 38 & $20.1 \%$ \\
\hline & Physical & 131 & $69.3 \%$ \\
\hline & Hearing & 15 & $7.9 \%$ \\
\hline & Mental & 3 & $1.6 \%$ \\
\hline & Multiple & 2 & $1.1 \%$ \\
\hline
\end{tabular}


46.6\% were undergraduate students with $29.1 \%$ undertaking diplomas in different fields and $24.3 \%$ undertaking post graduate studies. $45.55 \%$ of the respondents were earning below 3,00o JOD, but this may be associated with the fact that most were students and did not have a steady income source. $69.3 \%$ of the respondents had physical impairments while $20.1 \%$ were visually impaired and $7.9 \%$ had hearing impairments.

\subsection{Travel Constraints}

The issue of travel constraints was a major element of the research because they can have a significant influence on the capacity of individuals to engage in the activities and actually enjoy them. The results showed that intrinsic constraints were considered to be the most significant.

Table 2: Travel Constrains of Respondents

\begin{tabular}{lccc} 
Factors & Mean & SD & $\mathrm{n}$ \\
\hline Intrinsic constrains & 3.69 & 1.980 & \\
\hline Travel has requirements beyond my personal abilities & 4.03 & 1.870 & 189 \\
\hline Needing other people's help to do something & 3.71 & 1.620 & 189 \\
\hline Fear of doing something by myself & 3.88 & 2.102 & 189 \\
\hline Fear of causing discomfort and inconvenience to others & 3.52 & 1.670 & 189 \\
\hline Doctors' recommendations about my wellness & 3.04 & 1.860 & 189 \\
\hline Interactive constrains & 3.31 & 1.180 & \\
\hline Fear of being ignored by others & 3.82 & 1.043 & 189 \\
\hline Fear of being unable to make friends & 3.28 & 1.140 & 189 \\
\hline Fear of attracting others' interest & 2.99 & 1.250 & 189 \\
\hline Fear of getting hurt & 3.12 & 1.142 & 189 \\
\hline Fear of others' prejudice against me & 2.84 & 1.320 & 189 \\
\hline Environmental constraints & 3.48 & 2.070 & \\
\hline Inconvenient facilities & 3.62 & 1.950 & 189 \\
\hline My condition requires the use of assistive devices & 3.71 & 2.260 & 189 \\
\hline Inconvenient transportation facilities to use & 3.09 & 2.139 & 189 \\
\hline Poor physical conditions at the site & 2.95 & 2.050 & 189 \\
\hline Lack of physical ability to move easily around & 3.42 & 2.048 & 189
\end{tabular}

Their rating showed a mean of $3.69, \mathrm{SD}=1.980$. This was the highest mean score Environmental constraints had a mean score of 3.48, $\mathrm{SD}=\mathbf{2 . 0 7 0}$. The interactive constraints had a mean score of 3.31, $\mathrm{SD}=1.18 \mathrm{o}$, which was the lowest ion the group. In terms of the individual element of the travel constraints factors, those in the intrinsic category showed the highest scores. Most respondents were limited by travel requirements beyond their capabilities, fear of causing others' inconvenience, and being in a situation where they needed help from other people.

On the aspect of a motivation, the focus of the researchers was to evaluate the considerations that prevented the individuals from visiting historical sites.

Table 3: Motivation Measurements

\begin{tabular}{|c|c|c|c|}
\hline Measure & Mean & SD & $\mathrm{n}$ \\
\hline I do not care about this type of tourism activity & 2.93 & 1.38 & 189 \\
\hline I am indifferent; I don't think this type of tourist destination suits me & 3.04 & 1.62 & 189 \\
\hline I don't know; I think I wasted my time with this type of tourism & 2.79 & 1.46 & 189 \\
\hline
\end{tabular}

The motivational factor with the highest score among the respondents was the view that the type of tourism did not suit them. This had a score of $3.04, \mathrm{SD}=1.62$ followed by the view that the respondents 
did not care about that type of tourism activity. This had a mean score of $2.93, \mathrm{SD}=1.38$. The lowest score was in the respondents who reported that they felt such tourism activities would be a waste of their time $(2.79, \mathrm{SD}=1.46)$.

The intrinsic constraints seem to be the most relevant for the respondents where factors about their self-confidence and psychological requirements of engaging in the activities were the most significant in preening obstacles to their willingness to visit historical sites. Interactive constraints such as fear of getting hurt fear of prejudice or lack of experience in making friends were lest significant as travel constraints. Overall, it is al so clear that the ravel constraints showed relatively higher scores than the motivational factors. Therefore the constraining elements of travelling to these sites were more significant than the considerations preventing the individuals preventing the participants from visiting the specific sites.

A thematic analysis of the issues that the respondents cited as obstacles to their access to the historical sites included the absence of ramps to ease mobility for individuals on wheelchairs. Additionally, other barriers included the absence of guide persons to help people who are visually impaired. The visual impaired individuals also argued that they prefer to have signs at the sites written in braille to facilitate them. For people with hearing impairments, the absence of sign language interpreters at the sites was a major weakness. Not having people who can explain the sites to them in a way they can understand was cited as a major issue that discouraged people who are hearing impaired from visiting the sites.

\section{Discussion}

The findings from the current study indicate that disabled individuals in Jordan are affected by a wide range of factors. The study indicates that there are many issues that act as obstacles and archaeological to disabled people who are interested in tourism activities. The most important issues identified in the discussion as presenting obstacles to disabled people seeking to visit historical sites in Jordan include the intrinsic constraints that have been shown to be the most significant.

While interactive and environmental constraints also had relatively high mean scores, it seems that internal and attitudinal considerations or obstacles were more relevant. As a result, it seems that intrinsic factors are most significant obstacles that may be addressed through strategies for empowering individuals with disability. Issues such as lack of convenient facilities and facilities ranked lowly compared to their personal views about the effect of the disability.

The intrinsic motivations for engaging in tourism activities among these individuals have been cited as playing a major role in promoting tourism participation as cited in studies such as McCabe, Minnaert, and Diekmann (2012). Policy makers should focus on providing these individuals with more information about the features in tourist destinations and facilities. By giving the individuals accessible information about the features they have for supporting them, it would be possible to motivate them to participate and visit the historical sites for rest and relaxation.

The motivational measurements were not highly significant as considerations that influenced the willingness of individuals to engage in tourism activities. The views indicate that disabled people in Jordan have positive views about tourism activities as having the potential to improve their lives. It can be seen that motivational factors have a small impact on the willingness of individuals to engage in tourism activities. The intrinsic constraints that require most attention are those associated with the fear of causing discomfort to other people and needing their assistance in order to enjoy the facilities. This means tourism facility managers can motivate disabled people to engage in tourism activities more effectively if they provide them with assistive features and accessibility options that can enable them get by on their own without requiring assistance from other people.

\section{Conclusion}

The focus of the research was to identify the obstacles and constraints that prevent disabled people in 
Jordan from accessing tourist sites and destinations. It was based on the fact that accessible tourism has gained significance as an area of addressing their human rights. People with disabilities also have rights and should be allowed to access all types of activities for their enjoyment and to improve the quality of their lives. The concept of accessible tourism is a part of the long tail market movement where the needs of niche markets are addressed through customized products as opposed to average bundles.

The findings from this study indicate that the government and private sector in Jordan need to implemented features that make disabled people more aware of the features provided to make destinations more accessible to them. They should also work towards improving the features for these individuals in order to empower them that they can enjoy the facilities without requiring assistance from other people and hence inconveniencing them.

\section{References}

Allan, M. (2013). Disability Tourism: Why do Disabled People Engaging in Tourism Activities? European Journal of Social Sciences, 39(3), 480-486.

Allan, M. (2014). Accessible tourism in Jordan: travel constrains and motivations. European Journal of Tourism Research, 109-120.

Alsarayreh, M. N. (2019). Heritage tourism of archaeological sites in Jordan: Archaeological site employees' perspectives. African Journal of Hospitality, Tourism and Leisure, 8(4), 1-19.

Bahulis, D. et al (2012). Best Practice in Accessible Tourism: Inclusion, Disability, Ageing Population and Tourism. Great Britain. Short Run Press Ltd: pp. 1-12

Bazazo, I. K., \& Alananzeh, O. A. (2016). The Effect of Electronic Tourism in Enabling the Disabled Tourists to Communicate With the Touristic and Archaeological Sites Case Study - Jordan. European Scientific Journal, 12(5), 111-128.

Das, S. C., \& Rudra, R. K. (2015). Tourism Accessibility for Disabled Travellers: An Optimistic Concept on Tourism Industry in Bangladesh. International Journal of Advancements in Research \& Technology, 4(10), 37-49.

Deci, E. \& Ryan, R. (1991). A motivational approach to self: Integration in personality. In R. Dienstbier (Ed.), Nebraska Symposium on motivation. Perspectives on Motivation 38, 237-288).

European Commission. (2014). Economic impact and travel patterns of accessible tourism in Europe - final report. European Commission - DG Enterprise and Industry

GAN. (2017). Archaeological sites inaccessible for persons with disabilities in Jordan. Retrieved Dec 2, 2020, from https://globalaccessibilitynews.com/2017/o8/31/archaeological-sites-inaccessible-for-persons-withdisabilities-in-jordan/

Higher Council for the Rights of Persons with Disabilities. (2017). Law on the Rights of Persons with Disability. Amman: Jordan.

Lee, B. Agarwal, S. \& Kim, H J. (2011). Influence of travel constraints on people with disabilities intention to travel: an application of Seligman's helplessness theory. Tourism Management, 33, 569-579

McCabe, S. Minnaert, L., and Diekmann, A. (2012). Social Tourism in Europe: Theory and Practice. UK. Channel View Publication: pp. 156-16o.

Pedersen, M., Andersen, S., \& Jørgensen, S. (2016). Diskrimination og Handicap - forslag til et forbud mod diskrimination på grund af handicap. Copenhagen: Institut for Menneskerettigheder. Retrieved May 28, 2017 from http://www.ft.dk/samling/20161/almdel/sou/bilag/106/1711299.pdf

Sakarneh, M. (2014). Jordanian Education Reform between the Ideal and the Actual. Developing Country Studies, 4 (20), 65-73.

Sakarneh, M., Paterson, D. \& Minichiello, V. (2016). The Applicability of the NSW Quality Teaching Model to the Jordanian Primary School Context. Dirasat: Educational Sciences, Volume 43, Supplement. 4, 1773-1789.

Shaw, G., \& Coles, T. (2004). Disability, holiday making and the tourism industry in the UK: a preliminary survey. Tourism management, 25(3), 397-403.

Tecău, A. S., \& etal. (2019). Responsible Tourism-Integrating Families with Disabled Children in Tourist Destinations. Sustainability, 11, 4420-4437.

Thompson S. 2018. The current situation of persons with disabilities in Jordan. K4D Helpdesk Report. Brighton, UK: Institute of Development Studies.

World, D. (2013). World Facts and Statistics on Disabilities and Disability Issues. Retrieved Nov 30, 2020, from http://www.disabledworld.com/disability/statistics/\#ixzz2HJt 
WTO. (2020). Accessible tourism. Retrieved Nov 30, 2020, from https://www.unwto.org/accessibility

Wu YC.J., Cheng M.J. (2008) Accessible Tourism for the Disabled: Long Tail Theory. In: Lytras M.D., Carroll J.M., Damiani E., Tennyson R.D. (eds) Emerging Technologies and Information Systems for the Knowledge Society. WSKS 2008. Lecture Notes in Computer Science, vol 5288. Springer, Berlin, Heidelberg. https://doi.org/10.1007/978-3-540-87781-3_61.

Yau, M. K., McKercher, B., \& Packer, T. L. (2013). Travelling with a Disability - More than an Access Issue. Annals of Tourism Research, 31(4), 946-960. 